\title{
THE NEGATIVE EVIDENCE HYPOTHESIS: THE ACQUISITION OF THE DOUBLE-OBJECT CONSTRUCTION BY BRAZILIAN- PORTUGUESE ENGLISH BILINGUALS
}

\author{
Cândido Samuel Fonseca de Oliveira ${ }^{1^{*}}$
}

Alberto Gallo Araújo Penzin ${ }^{1 * *}$

${ }^{1}$ Centro Federal de Educação Tecnológica de Minas Gerais, Belo Horizonte, MG, Brasil

\begin{abstract}
This study aims to add to the body of evidence regarding the linguistic structures that seem to be more challenging in L2 acquisition than in L1 acquisition (DeKeyser, 2005; Ellis, 2008; Inagaki, 2001; Slabakova, 2014; Sorace, 2011). The Negative Evidence Hypothesis (NEH) (Oliveira, 2016) predicts that bilinguals are less sensitive than native speakers to violations resulted from the overgeneralization of an L2-specific rule. We tested this hypothesis by analyzing the behavior of Brazilian Portuguese-English bilinguals with different profiles towards the double-object construction in English with unlicensed verbs in two acceptability judgment tasks. The results corroborate the NEH by conveying that bilinguals gain sensitivity as they become more proficient, yet, the data suggest that not even when immersed in the L2, they become as sensitive as native speakers.

Keywords: Negative Evidence Hypothesis; Double-Object Construction; Learnability, Second Language Acquisition, Bilingualism.
\end{abstract}

\footnotetext{
"Possui licenciatura em língua inglesa (2010), mestrado (2013) e doutorado (2016) em estudos linguísticos pela Faculdade de Letras da Universidade Federal de Minas Gerais (UFMG). Atualmente é professor de língua inglesa do Centro Federal de Educação Tecnológica de Minas Gerais (CEFET-MG), professor colaborador do Programa de Pós-Graduação em Estudos Linguísticos da Universidade Federal de Minas Gerais (POSLIN/ UFMG) e membro do Laboratório de Psicolinguística da UFMG. Desenvolve trabalhos na área de linguística, atuando principalmente nos seguintes temas: bilinguismo, aquisição de segunda língua, representação e processamento linguístico, ensino e aprendizagem de inglês. Seu e-mail é: coliveira@cefetmg.br. ORCID: https://orcid.org/0000-0001-7578-6288 ${ }^{*}$ Formou-se bacharel em inglês (2015) com ênfase em estudos linguísticos pela Universidade Federal de Minas
Gerais (UFMG). Em 2016, ingressou-se no programa de pós-graduação em estudo linguísticos (POSLIN/
UFMG). Tornou-se mestre em linguística teórica e descritiva no ano de 2018. Atualmente, é professor de
língua inglesa, amante da linguística e sempre fascinado por questões relacionadas ao funcionamento da mente
bilíngue. Seu e-mail é: albertopenzin@hotmail.com. ORCID: https://orcid.org/0000-0001-5848-2215
} 


\section{Introduction}

In recent years there has been increasing interest in psycholinguistic studies which have educational implications (Maia, 2018). In the field of Second Language Acquisition (SLA), one of the topics that has been scrutinized through psycholinguistic methods and can be clearly linked to teaching methodologies is the limits of bilingualism or, more specifically, the differences between L1 and L2 acquisition that result in contrast between native speakers (henceforth NSs) and bilinguals in terms of linguistic knowledge even when the latter are highly proficient in the L2. It is important to emphasize that this is not to say that either NSs or bilinguals have better knowledge of a language. It only means that their knowledge seems to differ from one another, and some linguists have been trying to uncover these differences with experimental studies. Having a better comprehension of what linguistic aspects result in cognitive difficulties in second language acquisition can help L2 professionals develop more efficient teaching/ learning strategies and methods.

The Interface Hypothesis (Sorace, 2011) and the Bottleneck Hypothesis (Slabakova, 2014) have been recently debated in the literature, and they differ from each other as to what linguistic aspects they regard as the most difficult to be learned in L2 acquisition. The Interface Hypothesis, on the one hand, posits that the most difficult structures for bilinguals to master are those that require an interface between internal (syntax, morphology, phonology and semantics) and external parts of the grammar (pragmatics and discourse information). This hypothesis has been investigated mostly through bilinguals' behavior towards the use of null and overt subjects (McDonnell, 2019, Sorace \& Filliaci, 2006; Sorace \& Serratrice, 2009). The Bottleneck Hypothesis, on the other hand, postulates that the most difficult structure for bilinguals to acquire is functional morphology because of the amount of information they carry and of their cross-linguistic variation. This hypothesis has been supported by studies that show bilinguals' behavior towards agreement markers (Carneiro, 2017; Jensen, 2016, Mikhaylova, 2018).

In this paper, we formalize and test another hypothesis, which predicts that bilinguals will also encounter challenges directly linked to their perception of unfamiliar constructions bearing certain restrictions in the L2. In the next section we will elaborate further on this hypothesis.

\section{The Negative Evidence Hypothesis}

The Subset Principle (SP) in L2 acquisition (Inagaki, 2001; Okamoto, 2009; White, 1989) assumes that linguistic typology is responsible for the differences between L2 structures in terms of learning difficulty. According to this proposal, the L1 can be a superset or a subset of the L2 and vice-versa. The language that has a more restrictive grammar is the subset and the one with a more expanded grammar is the superset. It is important to note that a language can be a subset in relation to certain aspects of the grammar and a superset in relation to others. 
Take for example the argument-structure construction with the NP-VP$\mathrm{NP}-\mathrm{AP}^{1}$ pattern available in English and Brazilian Portuguese (henceforth, BP), we can assert that BP is a subset of English (or English is a superset of BP) in regard to the sequence NP-VP-NP-AP. English, on the one hand, licenses at least four constructions with this syntactic pattern, namely the small clause (1), the depictive (2), the pseudo-resultative (3), and the resultative (4). BP, on the other hand, licenses the small clause (5), the depictive (6), the pseudo-resultative (7), but not the resultative construction, whose structure can usually have a depictive reading (8). Hence, the grammar of $\mathrm{BP}$ is more restrictive than the grammar of English is in relation to the AP syntactic-semantic mapping in the aforementioned syntactic configuration.

(1) My father considers my hair long.

$$
\text { (small clause) }
$$

(2) My grandmother brushed my hair wet.

$$
\text { (depictive) }
$$

(3) The barber cut my hair short.

$$
\text { (pseudo-resultative) }
$$

(4) The breeze blew my hair dry.

$$
\text { (resultative) }
$$

(5) Meu pai considera o meu cabelo longo. My father considers DET my hair long. 'My father considers my hair long.'

$$
\text { (small clause) }
$$

(6) Minha avó escovou o meu cabelo molhado. My grandmother brush(PST) DET my hair wet.

'My grandmother brushed my hair wet'

$$
\text { (depictive) }
$$

(7) O barbeiro cortou o meu cabelo curto. DET barber cut(PST) DET my hair short. 'The barber cut my hair short.'

(pseudo-resultative)

(8) A brisa soprou o meu cabelo seco.

DET breeze blew DET my hair dry.

'The breeze blew my dry hair.' 
The SP proposes that learnability will vary according to the direction of the process (subset $\rightarrow$ superset or superset $\rightarrow$ subset). The prediction is that starting from a subset grammar towards a superset grammar is easier than the other way around. In other words, the model assumes that expanding (subset $\rightarrow$ superset) is easier than restraining one's grammar (superset $\rightarrow$ subset). In turn, in regard to the structure NP-VP-NP-AP, the model predicts that BP-English bilinguals will learn the resultative syntactic-semantic mapping in English more easily than English-BP bilinguals will learn the unavailability of such mapping in BP. The rationale is that in the first context, on the one hand, bilinguals will be favored by the input, which will naturally expose them to the hitherto-unknown structural rule, the resultative syntactic-semantic mapping. In the second context, on the other hand, bilinguals will have to learn that this structural rule is unavailable in the L2, notwithstanding the availability of other NP-VP-NP-AP structures. Therefore, the restraining context causes difficulty in bilinguals because the L2 input partially confirms that the L1 and the L2 are similar as to the NP-VP-NP-AP pattern and it does not provide evidence concerning the L1-specific rules that are unavailable in the L2.

Inagaki (2001) tested the Subset Principle with a bi-directional study analyzing the acquisition of English by Japanese speakers and the acquisition of Japanese by English speakers. The study focused on the learners' behavior towards manner-ofmotion verbs (walk) and directed motion verbs (go) in an acceptability judgment task. Both English and Japanese license directed motion verbs with a $\mathrm{PP}^{2}$ indicating a goal, but only English licenses manner-of-motion verbs in the same context. Thus, Japanese is a subset and English a superset as regards these verb types. The results corroborated the SP suggesting that Japanese-English bilinguals learned the new structure in their L2, and English-Japanese bilinguals failed to learn the absence of the same structure in their L2. Therefore, as predicted by the subset principle, bilinguals starting from a subset towards a superset grammar were more successful than bilinguals going in the opposite direction.

The SP does not make predictions as to bilinguals' behavior towards linguistic aspects that are unrelated to the L1. It proposes that bilinguals present some difficulty not overgeneralizing, in the L2, rules that are similar between the two languages, but broader in the L1. More specifically, it predicts that bilinguals do not easily learn that an L1 linguistic aspect is only partially available in the L2, because the exposure to the L2 input alone (positive evidence) cannot disconfirm this hypothesized broader grammar.

Following that line of thought, Oliveira (2016) raises a hypothesis as to bilinguals' behavior towards L2-specific rules: The Negative Evidence Hypothesis (henceforth, NEH). In this paper, we further explore this hypothesis and formalize it in the following manner:

Negative Evidence Hypothesis: bilinguals are likely to have difficulty learning that an L2-specific rule is only partially applicable. As a result, bilinguals will be less sensitive than NSs to violations resulted from the overgeneralization of an $\mathrm{L} 2$-specific rule. 
Whereas the SP makes predictions about structures that are typologically related, the NEH makes predictions about L2-specific rules. Nevertheless, both hypotheses share the same rationale: the input does not offer evidence concerning the unavailability of the missing linguistic aspect and bilinguals seem to use the absence of evidence as evidence of absence less than NSs do. Thus, both restraining grammatical knowledge from the L1 in the use of the L2 and learning L2-specific restrictions of structures that are not available in the L1 will be difficult for bilinguals.

One possible explanation as to why bilinguals are not as sensitive as monolinguals regarding the violations resulted from overgeneralization is the differences in the manner which the L1 and the L2 are acquired. If lexicalist approaches (Amaral \& Roeper, 2014) are correct, monolinguals specify each possibility of argument structure in each verb. Dissimilarly, bilinguals seem to be less likely to exhibit this sort of bottom-up acquisition, since they already have another - at times more dominant - grammar in their mind, and they usually do not have the same type of input as monolinguals do. In turn, bilinguals are likely to have a more top-down acquisition and use more general rules that may fail to include specific restrictions.

The nature of bilingualism may also play a role in this lack of sensitivity to certain linguistic violations. When using an L2, speakers frequently have to deal with structures that are not productive or even licensed in their previous grammar (L1) and figure out their correct interpretation. When using an L1, on the other hand, speakers are less likely to deal with completely new grammatical structures. Thus, it is more habitual for bilinguals than for NSs to assume that a new structure is correct and try to find the most suitable semantic-syntactic mapping for it. As a result, if this new structure is ungrammatical, bilinguals are not as likely as monolinguals to perceive it as so.

The behavior of BP-English bilinguals towards the NP-VP-NP-AP structure has been used to test both the SP and the NEH. As we have discussed above, English is a superset of BP as to the possible syntactic-semantic mapping of that structure. Both languages license the small-clause, depictive and pseudoresultative reading, but only English licenses the resultative reading. The SP predicts that English-BP bilinguals will have problems learning that the resultative construction is not available in BP, but BP-English bilinguals will not have problems learning the availability of this new structure in the L2 because they are favored by the input.

There are at least two pieces of empirical evidence supporting the predictions that BP-English bilinguals will successfully learn the resultative construction. Oliveira (2014) conducted an untimed acceptability judgment task with the magnitude estimation paradigm whose results indicated that non-immersed highly proficient BP-English bilinguals accepted sentences that instantiated the resultative construction (9) below as much as NSs did. Oliveira (2016) tested immersed and non-immersed highly proficient bilinguals in a timed acceptability judgment task using a 5-point Likert scale. The results also indicated that there 
were not significant differences between NSs and the two bilingual groups towards sentences such as (10). Therefore, the results of both studies support the SP prediction that BP-English bilinguals are perfectly capable of learning the resultative construction.

(9) One of the classrooms was very dirty, so Desiree swept it clean. The cook twisted the spoon and hammered it flat.

Oliveira (2016) has additional results that warrant further discussion. The author also conducted a maze-task (Forster, Guerrera \& Elliot, 2009), in order to analyze the processing of the AP in the resultative (10) above and the depictive constructions (11) below. The results indicated that the two bilingual groups processed the AP in the depictive construction, which is licensed both in the $\mathrm{L} 1$ and in the L2, as fast as NSs did. As to the AP in the resultative construction, NSs are significantly faster than non-immersed and immersed highly proficient bilinguals. However, it is important to point out that the difference between NSs and the immersed group was only marginally significant, and there was no significant difference between the two bilingual groups. The results from the acceptability judgment task suggest that the resultative construction is part of bilinguals' explicit knowledge, but the results from the maze-task suggest that this construction may not be as readily available in bilinguals' implicit knowledge as constructions licensed by both the L1 and the L2.

The man cut the carrot and ate it raw.

The NEH has different predictions regarding BP-English bilinguals' behavior towards the resultative construction. Since the resultative construction is unavailable in the L1, this hypothesis assumes that bilinguals will have difficulty perceiving violations resulted from overgeneralizations. The resultative construction, as discussed by Oliveira (2016), has many restrictions that could be used to test speakers' sensitivity to this type of violation. By way of illustration, the resultative construction does not license past participle adjectives and it has a strong tendency of not being formed by verbs originated from Romance languages (Goldberg \& Jackendoff, 2004).Furthermore, the resultative construction does not allow the resultative predicate to be topicalized or to appear in the form of itcleft construction (Ettlinger, 2005). Moreover, the resultative construction must be telic in order to be grammatical, but not all APs are able to induce telicity. As contended by Wechsler (2012), the resultative predicate AP has to be formed by a gradable, closed scale, maximum endpoint adjective (Figure 1). 
Figure 1 - Adjectives classification according to their scalar properties

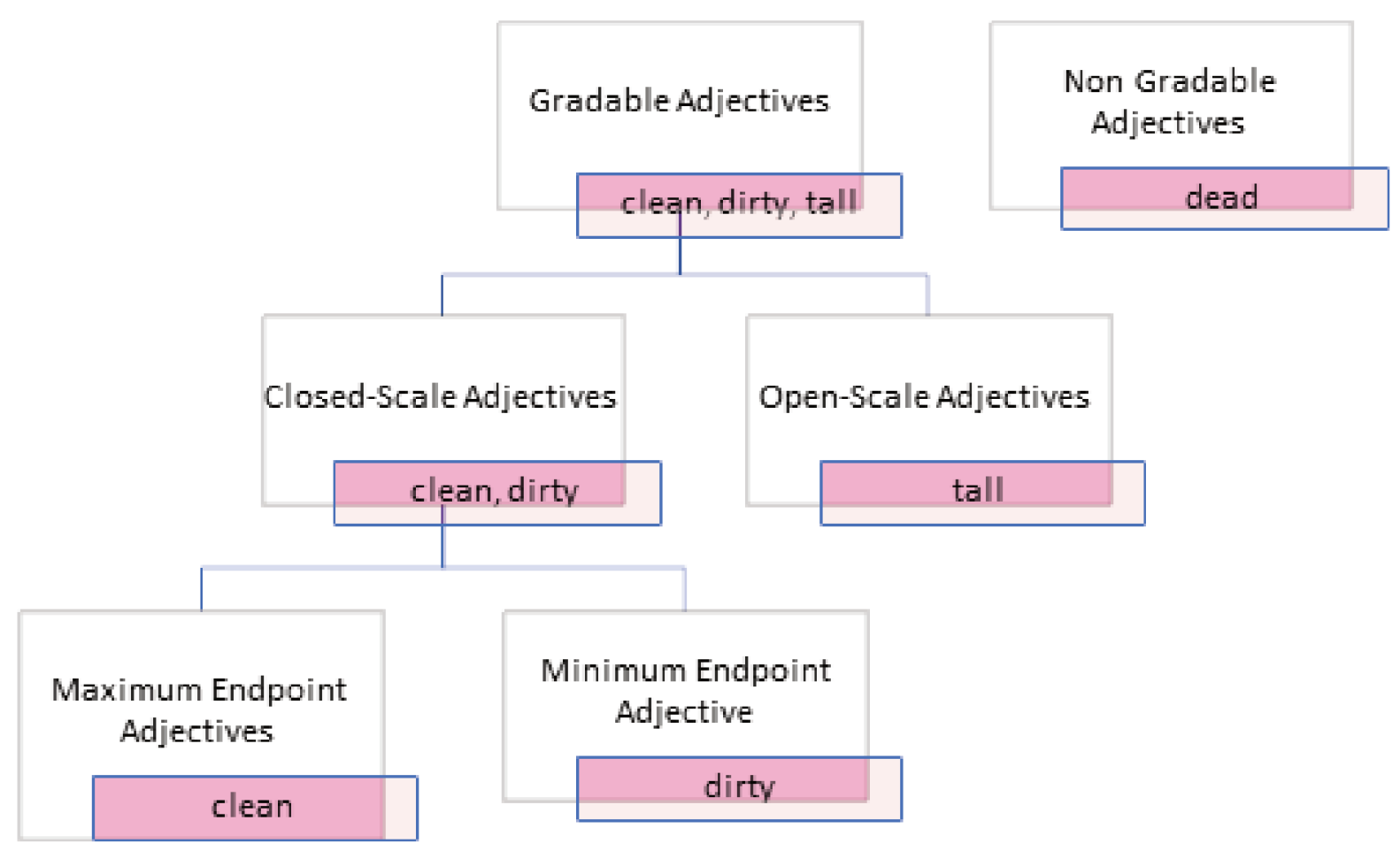

Fonte: Oliveira (2016)

Oliveira $(2014,2016)$ tested if BP-English bilinguals were sensitive to violations concerning this restriction in the resultative predicate AP. In both studies the author compared BP-English highly proficient bilinguals to English NSs regarding resultative sentences that violated the aforementioned rule. In other words, the author tested if these groups of speakers were sensitive to these adjective restrictions by analyzing their acceptability to sentences that had other types of adjectives that could also be interpreted as a result. In the first study, the author conducted an untimed acceptability judgment task with the magnitude estimation paradigm with non-immersed bilinguals and English NSs. The acceptability ratings for sentences such as (12) below exposed a statistically reliable difference between the bilingual and the NS groups. The former group exhibited higher acceptability ratings than the latter. In the second study, the timed acceptability judgment task with a Likert scale task yielded similar results to sentences such as (13). Both immersed and non-immersed bilingual groups exhibited higher acceptability ratings for the ungrammatical resultative sentences as compared to NSs. Thus, the results corroborated the NEH showing that bilinguals were not as sensitive as NSs to violations originated from overgeneralizations of an $\mathrm{L} 2$-specific rule.

(12) Chelsea had straightened her hair, but her little brother watered it curly.

(13) Josh found a spoon and twisted it broken. 
As opposed to what was observed in the processing of the AP in grammatical resultatives, data from the maze-task part of this second study did not reveal differences between the bilingual groups and the NS group. The results indicated that the use of adjectives that were not gradable, closed-scale, maximum end point generated similarly longer RTs in all the groups. Therefore, the higher processing cost does not seem to influence bilinguals' sensitivity to violations resulted from overgeneralization as much as it seems to influence monolinguals. This behavior seems to be in accordance with the NEH idea that it is more habitual for NSs than for bilinguals to assume that a new structure is wrong and, if this structure is indeed unlicensed, monolinguals are more likely than bilinguals to perceive it as so.

In this study, we aim to provide further evidence concerning the $\mathrm{NEH}$ by investigating bilinguals' sensitivity to restrictions of another argument structure construction: the double-object construction. More specifically, we will analyze bilinguals' responses to ungrammatical sentences that represent overgeneralizations of constructions with two direct objects to unlicensed verbs. Similarly to the resultative construction, the double-object construction is also unavailable in BP and, hence, the SP predicts that it is likely to be successfully acquired by BPEnglish bilinguals since they would be starting from a subset towards a superset grammar. The NEH, however, predicts that bilinguals will not be as sensitive as NSs to violations resulted from overgeneralizations. In the next section, we will briefly describe the argument-structure construction tested in our study.

\section{The double-object construction}

The double-object construction ${ }^{3}$ (also referred to as the DOC), a common syntactic configuration in English which encompasses a group of verbs with specific semantic-pragmatic properties licensing two direct objects, has continued to attract the attention of researchers in the field of second language acquisition (Agirre \& Mayo, 2014; Agirre, 2015; Yang \& Montrul, 2016; Zara, 2009; Zara, Oliveira \& Souza, 2013). In English, a verb such as give, the most productive verb associated with said construction, can be realized by two different syntactic structures represented below, (14) and (15).

Mary gave a book to John.

Mary gave John a book.

The apparent affinity among these two syntactic forms is termed by many authors in the linguistics literature as the dative alternation or shift (Hovav \& Levin, 2008; Larson, 1988; Levin, 1993; Pinker, 1989). ${ }^{4}$ It is said that the prepositional double-object structure (14) is semantically related to the doubledirect-object structure (15), but there are a number of conditions underlying a speaker's preference for one form instead of the other, in varying forms of linguistic expression (Zara, 2014). 
The fact that new verbs such as "text" can be used in both syntactic patterns attests that they are still productive constructions (Yang \& Montrul, 2016). Moreover, this sentential pattern is acquired first by English-speaking children (Campbell \& Tomasello, 2001), while also being the most ubiquitous in the English language in comparison to its prepositional counterpart. On the other hand, the existence of the DOC is not witnessed in most other languages (Hovav \& Levin, 2008). Therefore, it is quite plausible to assume that late L2 English learners will encounter a challenge in determining the limitations for the use of this construction; for instance, which verbs do and do not allow two direct objects - a fact that NSs are implicitly able to recognize. Although we acknowledge that there is a continual discussion in the field of linguistics regarding the crucial semantic-pragmatic motivations compelling speakers' predilection for the most appropriate construction in a specific communicative context, it is not the focus of the present study. The main concern of this study is to uncover whether late L2 learners of English acquire restrictions associated with the DOC. Before discussing the methodology employed to accomplish this objective, we present some interesting particularities regarding this construction.

There are various reasons why a word may not be licensed by the DOC. In order to understand the restrictions imposed by this construction, we will briefly bring to light its semantic underpinnings. For Pinker (1989, p. 75), dativization converts, by means of lexical rules, the predicate "cause $\mathrm{X}$ to go

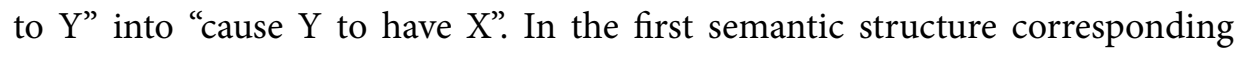
to the prepositional ditransitive form, the argument $\mathrm{Y}$ is a goal, whereas in the second structure tantamount to the double-object syntax, the same argument is a possessor (or a recipient); that is, an entity conscious of their ability to possess the theme argument. The author exemplifies this distinction by demonstrating that a phrase such as 'drive a car to Chicago' is possible, whereas 'drive Chicago a car' is ungrammatical, since Chicago cannot effectively possess the car. While we do not wholeheartedly adhere to Pinker's lexical conversion rule, this example illustrates quite well the subtle semantic distinction between the Y-arguments of both constructions.

According to Agirre (2014), the DPs need to create a possession relationship, i.e. the referent of the first object has a possession relationship with the second object. Goldberg (1995) also commented on the restrictions related to recipient arguments requiring the ability to possess the object denoted by the theme, as is demonstrated below by contrasting examples (16) and (17). Joe cleared Sam a place on the floor. ${ }^{\star}$ Joe cleared Sam the floor.

This distinction can be explained on the grounds that Sam cannot successfully receive the entire floor, but he can occupy part of it. For a verb such as throw, as is demonstrated in the following examples, the recipient argument of a ditransitive 
prepositional construction can be an inanimate entity (18), whereas these verbs can only license the DOC if the adjacent argument is an animate recipient (20), but not an inanimate entity as is attested in (19).

(18) Smith threw the ball to the first base.

(19) *Smith threw the first base the ball.

(20) Smith threw the first baseman the ball. ${ }^{5}$

Another relevant constraint involving the DOC has to do with verbs that are very similar in meaning, but do not pose the same grammaticality status for the two syntactic realizations of the alternation. Harley (2007) and Agirre (2014) both demonstrated that one of the reasons is related to linguistic typology, since English verbs which inherit a Latinate root,(21) and (22), exemplified below, generally do not license the argument structure projecting two direct objects, while verbs that have a Germanic root, (23) and (24), do allow this kind of syntactic distribution. Verb pairs which are almost semantically identical, such as buy/purchase and give/donate, are some of these examples.

(21) *John purchased Mary a car.

(22) *John donated Mary his money.

(23) John bought Mary a car.

(24) John gave Mary his money.

Agirre (2014) has pointed to recent studies which show that word size is also a feature that determines if a nominal phrase can be licensed as the first direct object of the DOC. Hovav \& Levin (2008) stated that for the most part an argument expressible as the first object of the DOC can also appear as the object of the preposition "to" in a dative prepositional construction. However, in some instances an argument which can appear as a first object, (25) and (26), cannot appear in a to-phrase, (27) and (28). Thus, certain expressions only allow the twodirect-object variant as is exemplified below.

(25) The noise gave Terry a headache.

(26) The recession cost my grandfather a raise.

(27) ${ }^{*}$ The noise gave a headache to Terry.

(28) ${ }^{*}$ The recession cost a raise to my grandfather.

The examples above motivate the question involving what proficiency level or language experience is potentially necessary for L2 learners of English to become sensitive to restrictions concerning the DOC. In L2 acquisition of English, some studies have shown that learners acquire this construction in the later stages (Hamdan, 1994; Kang, 2011; Mazurkewich, 1984; Oh, 2006; Zeddari, 2009), ${ }^{6}$ but there is still a very limited amount of evidence shedding a light on how bilinguals perceive the restrictions of the construction in question. In the 
following paragraphs, we will briefly mention four studies which bear some notable contributions to the present work.

Agirre (2014) tested whether Spanish-English bilinguals were sensitive to the Latinate and the possessor constraint. The author compared the behavior of 90 bilinguals at different levels of proficiency ( 30 beginners, 30 intermediate and 30 advanced) towards grammatical and unlicensed DOC. For this, two acceptability judgment tasks were used, one with self-paced reading and the other with automatic-paced reading. The results revealed overgeneralization at all levels, as predicted by the Negative Evidence Hypothesis, but they decreased as proficiency increased. In our study we will also examine if proficiency plays a role in mitigating the overgeneralization of the DOC to unlicensed verbs. As will be discussed in the following paragraphs, a similar pattern was observed in the same bilingual population tested in our study.

Two previous experimental studies which examined the acquisition of the DOC have yielded data from BP-English bilinguals. Zara (2009) and Zara, Oliveira and Souza (2013) found that only the highly proficient bilinguals accepted sentences with two direct objects in English. The low proficiency group displayed the tendency to reject this structure, suggesting that they had not yet reached the acquisition threshold. However, these studies as the others reviewed in Zara (2014) only asked their participants to evaluate grammatical instances of the DOC. The added challenge of discerning the licit sentences from the illicit ones, a meaningful aspect of the acquisition process, remained to be tested.

Zara (2014) conducted research for her Doctoral dissertation which employed corpora analysis of statistical distribution of the DOC involving English NSs and Brazilian L2 late English learners. To assess the prevalence of this construction among NSs of English, the author considered two sub-corpora, Written (written) and Spoken (oral), components of a larger British corpus called the International Corpus of English (ICE-GB). It is comprised of 200 written texts (423,702 words) and 300 spoken texts (637,562 words) gathered from 1990 to 1993. To observe the same data for the Brazilian late learners of English, she utilized two distinct corpora Br-ICLE and LINDSEI-BR. Br-ICLE is a written English sub-corpus of the International Corpus of Learner English. When this corpus was analyzed, it contained 159,364 words, containing 332 texts each from individual Brazilian university students who are learners of English as an L2. LINDSEI-BR is the Brazilian component of the Louvain International Database of Spoken English Interlanguage, an online spoken sub-corpus consisting of 30,952 words from 15 L2 speakers of English.

The author found that BP, late L2 learners of English who had achieved intermediary or high proficiency levels were sensitive to the appropriate contexts for the use of the DOC in their L2. The same bilingual population was also able to distinguish the appropriate use of said construction in written language. Notwithstanding, according to the results of this research, due to the fact that the prepositional ditransitive construction is the most ubiquitous in $\mathrm{BP}$, it is also acquired earlier in the bilinguals' L2. This conclusion supports the data uncovered 
in Zara et al. (2013). Thus, L1 frequency effects influenced the acquisition (as well as the absence) of certain grammatical features inherent to BP's equivalent of the ditransitive structure, i.e., the prepositional double object. Table 1 below, translated from Zara (2014)'s, displays the distribution of the different syntactic configurations associated with dative constructions in L1 and L2 English.

Table 1- Distribution of dative constructions in English L1 and L2 corpora

\begin{tabular}{l|l|l|l}
\hline Corpus & DOC & $\begin{array}{l}\text { Prepositional } \\
\text { ditransitive }\end{array}$ & $\begin{array}{l}\text { Inverted prep. } \\
\text { ditransitive }\end{array}$ \\
Written (L1) & $79.01 \%(271)$ & $20.12 \%(69)$ & $0.87 \%(3)$ \\
Spoken (L1) & $82.56 \%(426)$ & $17.44 \%(90)$ & $0.00 \%(0)$ \\
Br-ICLE (L2) & $58.54 \%(120)$ & $34.63 \%(71)$ & $6.83 \%(14)$ \\
LINDSEI-BR (L2) & $61.90 \%(13)$ & $38.10 \%(8)$ & $0.00 \%(0)$ \\
\hline
\end{tabular}

Note. Adapted and translated from "To give you a book or to give a book to you: um estudo sobre a variação sintática na expressão linguística de eventos de transferência de posse na interlíngua português/inglês" by J. Zara, 2014, Doctoral dissertation, p. 130, Universidade Federal de Minas Gerais, Belo Horizonte, Brazil.

As can be interpreted from the table above, the DOC represents a large majority of the instances of all dative construction variants in the L1 English corpora, Written and Spoken. These occurrences were significantly higher than those found in the L2 corpora, Br-ICLE and LINDSEI-BR. Even though the L2 corpora analyzed were not of significant size, the results show that the instances of DOC in comparison to the other analogous constructions also represent the majority of the instances in the corpora of L2 learners; hence it seems to imply that these bilinguals were able to acquire at least some of the appropriate uses of the DOC. However, the higher ratio of occurrences of DOC over the other two constructions witnessed in both L1 corpora is evidence that BP-English L2 learners still prefer the construction far less.

One intriguing caveat to note is that some Brazilian researchers posited the existence or the emergence of the DOC in some dialects of BP spoken in different regions of the country (Gomes, 2003; Lucchesi \& Mello, 2009; Scher, 1996), one of which being precisely the region where the current study was conducted. This fact would entail that perhaps the DOC is not a foreign grammatical structure to NSs of BP after all. In an attempt to provide further support to such a claim, Zara (2014) also analyzed two native BP corpora for instances of five different dative constructions which are interrelated (Table 2, below).The first corpus, Humanas is a $\mathrm{BP}$ online corpus which contains $1,786,289$ words from a variety of written genres related to the Human Sciences, collected from websites, newspapers, journals and magazines. It is a sub-corpus of a larger corpus Lácio-Web. The second corpus, C-ORAL-BRASIL is a spontaneous speech corpus of BP collected from the metropolitan region of the city of Belo Horizonte, Brazil. At the moment its data were analyzed, it was comprised of 208,130 words from 139 texts which represent a variety of communicative situations from public and private settings. 
Table2 -Corpora analysis of five dative constructions in BP

\begin{tabular}{|c|c|c|}
\hline \multirow[b]{2}{*}{ Construction in BP } & \multicolumn{2}{|c|}{ BP corpora } \\
\hline & Humanas & C-ORAL-BRASIL \\
\hline $\begin{array}{l}\text { 1. Prepositionalditransitive } \\
\text { Maria deu um livro para João. } \\
\text { Mary give(PST) DET book PREP John. } \\
\text { 'Mary gave a book to John.' }\end{array}$ & $58.23 \%(601)$ & $45.93 \%(79)$ \\
\hline $\begin{array}{l}\text { 2. Inverted prep. ditransitive } \\
\text { Maria deu para João um livro. } \\
\text { Mary give(PST) PREP John DET book. } \\
\text { 'Mary gave to John a book.' }\end{array}$ & $22.67 \%(234)$ & $7.56 \%(13)$ \\
\hline $\begin{array}{l}\text { 3. Ditransitive(i.e. DOC) } \\
\text { Maria deu João um livro. } \\
\text { Mary give(PST) John DET book. } \\
\text { 'Mary gave John a book.' }\end{array}$ & $7.18 \%(74)$ & $2.91 \%(5)$ \\
\hline $\begin{array}{l}\text { 4. Invertedditransitive } \\
\text { Maria deu um livro João. } \\
\text { Mary give(PST) DET book John. } \\
\text { '*Mary gave a book John. }\end{array}$ & $0.00 \%(0)$ & $0.58 \%(1)$ \\
\hline $\begin{array}{l}\text { 5. Verbpronoun } \\
\text { Maria lhe deu um livro. } \\
\text { Mary [to him] give(PST) DET book. } \\
\text { '*Mary him gave a book.' }\end{array}$ & $11.92 \%(123)$ & $43.02 \%(74)$ \\
\hline
\end{tabular}

Note. Adapted and translated from "To give you a book or to give a book to you: um estudo sobre a variação sintática na expressão linguística de eventos de transferência de posse na interlíngua português/inglês” by J. Zara, 2014, Doctoral dissertation, p. 124, Universidade Federal de Minas Gerais, Belo Horizonte, Brazil.

The author found that the prepositional ditransitive represented the majority of occurrences. The information exhibited above reveals that the occurrence of the construction with two direct objects in BP has an almost negligible status in the language, representing less than $10 \%$ of occurrences. Considering both corpora evidence previously presented, we can reach a tentative conclusion that, for learners of English as an L2, the acquisition of the DOC still represents somewhat of a novelty, and their preference for the prepositional ditransitive construction in English is heavily guided by the knowledge of BP, their L1.

In the next section we will present the experiments we constructed to assess the acquisition of the DOC by BP-English bilinguals in light of the NEH.

\section{Methods}

We tested the NEH by analyzing the behavior of Brazilian PortugueseEnglish bilinguals towards the DOC in two acceptability judgment tasks. Our measurements attempted to evaluate the sensitivity of these bilinguals to verb violations of the DOC. More specifically, we analyzed bilinguals' responses to illicit sentences that represented overgeneralizations of the DOC to unlicensed verbs (The woman donated the student a laptop last week) and to licensed DOC 
sentences (The grandma offered the boy a candy for dessert). In the first test, we compared bilinguals at two different levels of proficiency in order to observe if they encounter difficulties in differentiating these two types of sentences, as predicted by the NEH, and if they become more sensitive to this type of verb violation as they become more proficient. In the second experiment, we tested if high proficiency bilinguals (immersed in the L1 and immersed in the L2) are indeed less sensitive to the aforementioned violations as compared to NSs. The comparison between immersed and non-immersed bilinguals will also allow us to observe if immersion plays a role in the acquisition of this construction.

The two acceptability judgment tasks had a different format because they were also part of two unrelated studies. In the first acceptability judgment task, sentences were displayed with a moving-window word-by-word self-paced reading format, whereas in the second task, sentences were displayed all at once with a six-second time ceiling. We also compared the data from the high proficiency bilinguals in the two experiments in order to observe if the two different formats of acceptability judgment tasks resulted in significant differences.

\section{Experiment 1}

In Experiment 1, we conducted an acceptability judgment task with low and high proficiency Brazilian-Portuguese English bilinguals. This task consisted of target sentences (DOC with verb violation), control sentences (licensed DOC) and distractor sentences in English. Based on the results from Agirre (2014), we expected low proficiency bilinguals to be less sensitive to the DOC restrictions than high proficiency bilinguals.

The predictor variables for this experiment were the two sentence types (DOC with verb violation and licensed DOC) and the linguistic profile (low proficiency bilinguals and high proficiency bilinguals). The outcome variables were the acceptability ratings given by the participants to the instances of the aforementioned constructions.

\section{Participants}

Participants were classified as low proficiency and high proficiency with the VLT - Vocabulary Levels Test - (Nation, 1990). The VLT is a word association test, in which participants are given a group of words and a group of their possible meaning and they should correctly link them. The further the participant moves in the test the less frequent are the given words. Participants had ten minutes to do the test. The VLT classifies the participants into 5 different levels and, similarly to previous studies (Fernández, Souza \& Carando, 2017; Fontoura, 2018; Oliveira, 2016; Penzin, 2018; Souza \& Oliveira, 2014), we considered level 3 low proficiency and level 5 high proficiency. The efficiency of the VLT in separating high proficiency from low proficiency bilinguals has been attested by Souza and Silva (2015). The authors determined that a low proficiency bilingual, that is, 
a person who has limited knowledge of English, is able to recognize the fivethousand most frequent words in the language, whereas high proficiency speakers would possess the vocabulary akin to ten-thousand most frequent words.

In total, 36 participants performed the task, half of which were low proficiency bilinguals, whereas the other half was formed by high proficiency bilinguals. The low proficiency group reported an average age of 24 (range of 19 to 36) and the high proficiency group reported an average age of 25 (range of 19 to 32). All the participants lived in Brazil and had spent most of their lives in their homeland.

\section{Materials}

Participants read and rated the acceptability of 72 sentences in English. This experimental session consisted of 8 target sentences, 8 controls and 56 distractors. Target items were comprised of sentences with verbs which do not license the DOC. We termed them DOC with verb violation, such as in (29) and (30).

*The woman donated the student a laptop last week. *The driver delivered the client the product very quickly

The target sentences were controlled for word frequency as well as for the number of syllables of the internal arguments. ${ }^{7}$ All words used to form the target stimuli were in the band of the five-thousand most frequent words. Moreover, all the objects had from two to four syllables, which were in accordance with the knowledge of participants at level 3 - or above - of the VLT. In Table 3 below, all the verbs used to create the target sentences are displayed along with their frequency according to the COCA Corpus.

Table 3 -Verbs used to create the target sentences (i.e. verb violation condition), their frequency, and number of occurrences according to the COCA corpus

\begin{tabular}{lll}
\hline Verb & Frequency & Occurrences \\
\hline carry & 488 & 79513 \\
donate & 4134 & 6606 \\
deliver & 1295 & 29169 \\
explain & 481 & 80797 \\
present & 820 & 49659 \\
purchase & 2168 & 16064 \\
report & 451 & 88138 \\
whisper & 2467 & 15383 \\
\hline
\end{tabular}

Note. Source: own elaboration. The verb whisper is the only verb used in this study that has a Germanic origin. We included this verb as it is representative of a clear unlicensed example of the DOC. For reasons unknown to us, it is the only verb we found with the same etymology of verbs which allow the DOC, yet it behaves differently regarding the construction in question. 
As can be verified in the Table above, most verbs used to construct the target sentences were well below the five-thousand-word frequency threshold. Thus, no bilingual participants evaluated in this study - whether low or high proficiency - would generally lack the knowledge of any of the verbs presented above. The only verb which yielded an above four-thousand frequency band is donate which, despite its status in English, would pose no sense of oddity among NSs of BP, as this Latinate verb is quite common in their L1.

The control items depicted below were comprised of grammatical DOC sentences, as in (31) and (32).

(31) The grandma offered the boy a candy for dessert. My uncle gave his sister a gift he liked.

The entire experimental corpus was balanced for grammaticality, i.e., the 8 target sentences were ungrammatical, whereas the 8 control sentences were grammatical. Additionally, 50\% distractor sentences were grammatical and the other $50 \%$ were ungrammatical. The 28 grammatical distractors are examples of clearly grammatical sentences, i.e., basic declarative sentences. Conversely, the ungrammatical distractors are instances of categorically ungrammatical sentences, i.e., sentences with shuffled words.

\section{Procedures}

The participants volunteered to participate in the experiment by responding to an email sent to UFMG students who attended a few different courses, or a post on the Letters college community of the social network Facebook. All the undergraduate students received credits for their participation.

The experiment started with the instructions and a practice session with 10 sentences, in order to familiarize participants with the task. One relevant experimental procedure was to inform the participants that their judgment was supposed to be made based on both speech and writing, i.e., things they could hear from a member of their linguistic community, expressions which were possible in their language, and not on normative writing conventions. As has been previously stated, the sentences were displayed to the participants in English with a moving-window word-by-word self-paced reading format (Fig. 2).

Figure 2 - Representation of how the stimuli were presented in Experiment 1

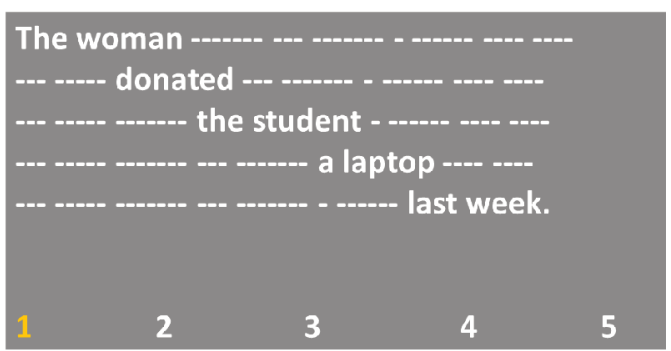


Participants used the Space key to read past each sentence fragment. The first time they pressed the Space key, the first line of the figure above appeared. They pressed the same key four more times, each time corresponding to the following lines, until they reached the last line of the figure, the five-point Likert scale. After reading the entire sentence, they were instructed to rate its acceptability in a scale of five values $(1,2,3,4$ or 5$)$. The chart below represents each of the numerical values of the Likert scale.

Figure 3 - Representation of theLikert scale in English

Judgment in English
1- Totally unacceptable
2- Very ill-formed, almost unacceptable
3- Ill-formed, but maybe acceptable
4- Slightly ill-formed, almost perfect
5- Totally perfect

The following section will be concerned with the statistical analyses of Experiment 1 .

\section{Results}

The results from Experiment 1 are illustrated in Graph 1 and Graph 2. As we can observe, both bilinguals and monolinguals gave high acceptability ratings to both DOC with verb violation (target) and the licensed DOC (control).

Graph 1 - Experiment 1 comparison between high-proficiency bilinguals and low-proficiency bilinguals' acceptability ratings towards each sentence group

\section{Acceptability Ratings}

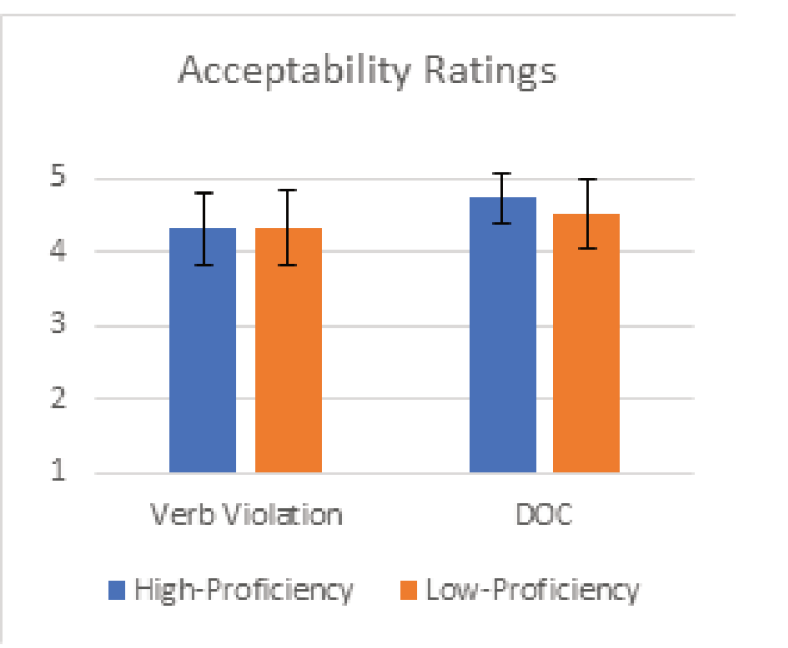

Graph 2 - Experiment 1 comparison between acceptability ratings of eachsentence group within high-proficiency bilingual and lowproficiencybilingual groups

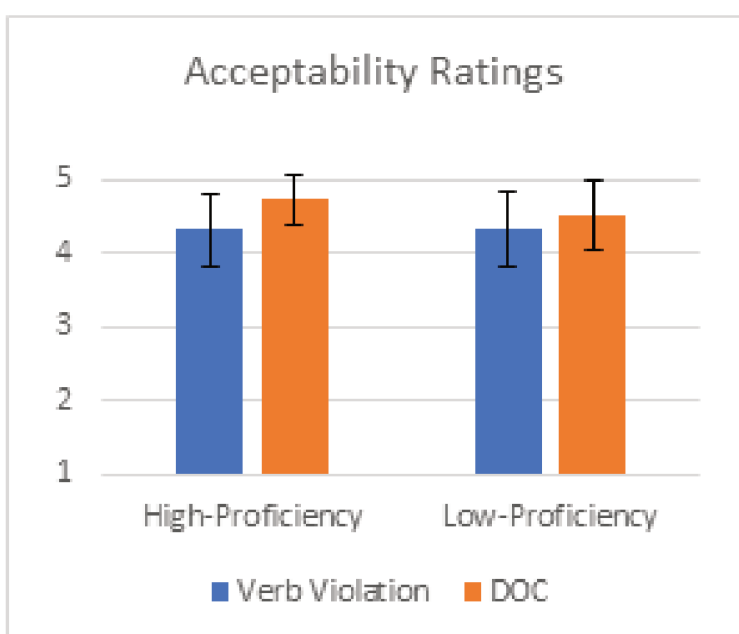

The acceptability ratings were tested for normality with the Shapiro-Wilk test. All the data distributions analyzed in Experiment 1differed from the normal 
distribution: high proficiency bilinguals/ DOC with verb violation $(\mathrm{W}=.758$, $\mathrm{p}<.001)$, high proficiency bilinguals/ licensed DOC $(\mathrm{W}=.253, \mathrm{p}<.001)$, low proficiency bilinguals/ DOC with verb violation $(\mathrm{W}=.769, \mathrm{p}<.001)$ and low proficiency/ licensed DOC $(\mathrm{W}=.695, \mathrm{p}<.001)$. Given the non-normality of the distributions observed, we conducted an analysis with a nonparametric comparison of central tendencies, namely the Mann-Whitney test.

Only one of our comparisons yielded significant differences. As illustrated in Graph 1, we compared both bilingual groups in relation to their acceptability rating towards both sentence types. Low proficiency bilinguals did not differ significantly from high proficiency bilinguals, neither as to their acceptability ratings towards the DOC with verb violation $(\mathrm{U}=157.500, \mathrm{p}=.89)$ with a mean rank of 18.25 for high proficiency bilinguals and 18.75 for low proficiency groups nor to their acceptability ratings towards the licensed $\mathrm{DOC}(\mathrm{U}=112.000, \mathrm{p}=.11)$ with a mean rank of 21.28 for the high proficiency group and 15.72 for the low proficiency group. As illustrated in Graph 2, we also compared the difference between the two sentence types within each bilingual group. The low proficiency group's acceptability ratings towards the DOC with verb violation and the licensed DOC did not yield significant difference $(\mathrm{U}=107.500, \mathrm{p}=.09)$, with a mean rank of 15.74 for the DOC with verb violation and 21.53 for the licit DOC. The high proficiency group's acceptability ratings were significantly lower for the DOC with verb violation $(U=75.000, p<.01)$ with a mean rank of 13.67 for DOC with verb violation and of 23.33 for the licensed DOC.

Therefore, our results are in accordance with Agirre (2014) and they partially support the NEH. The results from Experiment 1 corroborate the NEH prediction that bilinguals are likely to have difficulty learning that an L2-specific rule is only partially applicable by showing that low proficiency bilinguals do not even differentiate licensed from unlicensed DOC. Nevertheless, our results also show that bilinguals with high proficiency are indeed capable of distinguishing licensed DOC sentences from unlicensed ones. In the next experiment, in order to fully test the NEH, we will analyze if high proficiency bilinguals immersed in the L1 and high proficiency bilinguals immersed in the L2 are less sensitive to violations resulted from the overgeneralization of an L2-specific rule as compared to NSs.

\section{Experiment 2}

In Experiment 2, we conducted a timed acceptability judgment task with a six-second time limit, based on the suggestions of Souza, Oliveira, Soares-Silva, Penzin and Santos (2015). Two groups of bilinguals and one group of NSs of English read sentences similar to those in Experiment 1. We used the same verbs and structures for target and control items, but these sentences were not identical to Experiment 1. Thus, target items were instances of DOC with an unlicensed verb, whereas control items were grammatical instances of the DOC. Based on the NEH, we expected NSs to give lower acceptability ratings to the DOC with verb violation due to a possible stronger sensitivity to this type of restriction. 
Also, we predicted that there would not be differences between the immersed and the non-immersed bilingual groups since this overgeneralization we hypothesize is a byproduct of the manner of acquisition (the more bottom-up the acquisition is the more sensitive the speaker is) and not to the amount or type of input bilinguals receive.

The predictor variables were the two sentence types (DOC with verb violation and grammatical DOC) and the linguistic profile (non-immersed high proficiency bilinguals, immersed high proficiency bilinguals and NSs). The outcome variables were the acceptability ratings given by the participants to the instances of the aforementioned constructions.

\section{Participants}

In total, 61 people voluntarily took part in experiment two. They were grouped into English monolinguals (18), immersed bilinguals (18) and nonimmersed bilinguals (18). Both bilingual groups were classified as high proficiency in the VLT test. English monolinguals were residents of Madison/WI in the United States and they reported an average age of 25(range of 21 to 31). Immersed bilinguals were residents of the Boston/MA metropolitan area in the United States and their average age was 29 (range of 22 to 33). Non-immersed bilinguals were residents of Belo Horizonte/MG metropolitan area in Brazil and they were in average 26 years old(range of 19 to 32).Participants' minimal level of education was some college or post-secondary coursework.

The task was conducted with a within subject design and, hence, all participants were exposed to both the sentences with verb violations and the licensed DOC.

\section{Materials}

Participants read and rated the acceptability of 96 sentences in English. Before that, they took part in a training session with 15 sentences. This experimental session consisted of 8 target sentences, 8 controls and 80 distractors. We utilized the same verbs from Experiment 1in the DOC sentences with verb violation (33) and (34) and licensed DOC (35) and (36), but not the same sentences, as illustrated in the examples below. Thus, we had similar target and control items in both experiments. Furthermore, we utilized distractor sentences that were similar to those in Experiment 1 and they were also balanced according to their grammaticality status. Differently from Experiment 1, the sentences were not displayed in chunks. The sentences were fully exhibited in the screen until the participants rated their acceptability with a time-limit of six seconds.

(33) *The neighbor donated the kids a bike.

(34) * Mary delivered Josh the pizza.

(35) Charles offered his niece a job. 

The student gave the teacher an apple.

\section{Procedures}

We utilized the same procedures from Experiment 1.

\section{Results}

The results from Experiment 2 are presented in Graph 3 and Graph 4. Both bilingual groups and the monolingual group gave high acceptability ratings to both DOC with verb violation and the licensed DOC.

Graph3 - Experiment 2 comparison between immersed bilinguals, non-immersed bilinguals and monolinguals' acceptability ratings towards each sentence group.

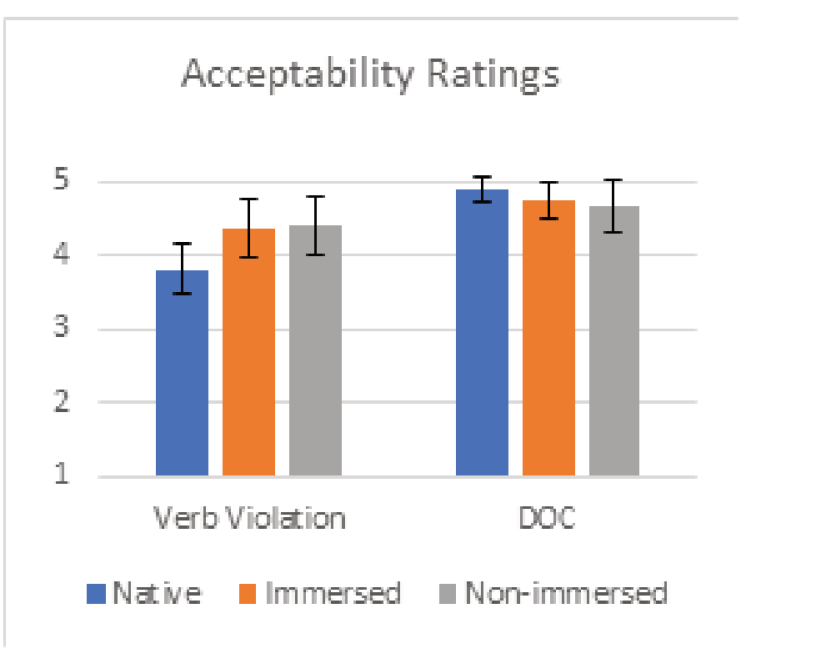

Graph 4 - Experiment 2comparison between acceptability ratings to each sentence group within immersed bilingual, non-immersed bilingual and native groups.

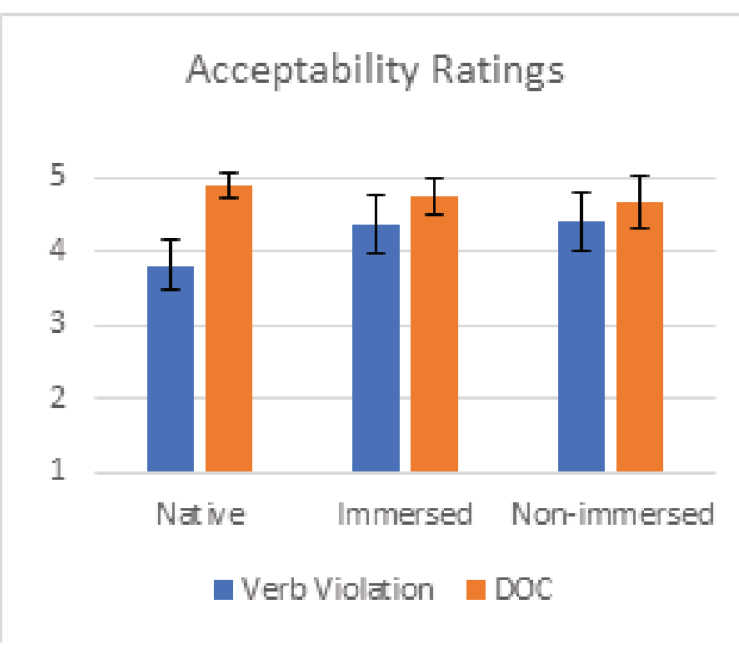

We tested the data for normality with the Shapiro-Wilk test. As in Experiment 1, all acceptability ratings distributions differed from the normal distribution: natives/ DOC with verb violation ( $\mathrm{W}=.540, \mathrm{p}<.001)$, natives/ licensed DOC (W $=.481, \mathrm{p}<.001)$, immersed bilinguals/ DOC with verb violation $(\mathrm{W}=.534, \mathrm{p}<$ $.001)$, immersed bilinguals/ licensed DOC $(\mathrm{W}=.531, \mathrm{p}<.001)$, non-immersed bilingual/ DOC with verb violation $(\mathrm{W}=.378, \mathrm{p}<.001)$ and non-immersed bilingual/ licensed DOC $(\mathrm{W}=.662, \mathrm{p}<.001)$. Since the data did not have a normal distribution, we conducted our analysis with two non-parametric tests, namely Kruskal-Wallis and Mann-Whitney.

As illustrated in Graph 3, we compared all groups of speaker sin relation to their acceptability ratings towards both sentence types. The Kruskal-Wallis test showed that there was a statistically reliable difference as to the acceptability ratings towards the DOC with verb violation $(\chi 2=19.410, \mathrm{p}<.001)$ with a mean rank of 14.22 for NSs, 33.42 for immersed bilinguals and 34.86 for non-immersed bilinguals. The Mann-Whitney test adjusted with Bonferroni correction indicated that NSs differed significantly from immersed bilinguals $(U=47.500, p<.001)$ 
with a mean rank of 12.14 for NSs and 24.86 for immersed bilinguals. NSs also differed significantly from non-immersed bilinguals $(\mathrm{U}=37.500, \mathrm{p}<.001)$ with a mean rank of 11.58 for NSs and 18.94 for non-immersed bilinguals. With a mean rank of 18.06 for immersed bilinguals and 18.94 for non-immersed bilinguals, the bilingual groups' acceptability ratings towards the DOC with verb violation did not yield significant difference $(\mathrm{U}=154.000, \mathrm{p}<.815)$. As to the acceptability ratings towards the licensed DOC, the Kruskal-Wallis indicated that there was not a significant difference between the three groups of speakers $(\chi 2=4.857, \mathrm{p}=.09)$ with a mean rank of 33.72 for NSs, 24.72 for immersed bilinguals and 24.06for non-immersed bilinguals. Therefore, bilinguals behaved similarly to NSs towards the licensed DOC and, as predicted by the NEH, they were less sensitive than NSs towards the DOC with verb violation. Also, in accordance with our predictions, immersion did not play a role in bilinguals' sensitivity tothe L2 violation.

We also utilized the Mann-Whitney to test the comparison illustrated in Graph 4. The NS group's acceptability ratings towards the DOC with verb violation and the licensed DOC yielded a significant difference $(U=.000$, $\mathrm{p}<.001$ ) with a mean rank of 9.50 for the DOC with verb violation and 27.50 for the licensed DOC. The immersed bilingual group's acceptability ratings towards the DOC with verb violation and the licensed DOC also yielded a reliable difference $(U=72.500, p<.01)$ with a mean rank of 13.53 for the DOC with verb violation and 23.47 for the licensed DOC. The non-immersed bilingual group's acceptability ratings towards the DOC with verb violation and the licensed DOC were also significantly different $(U=100.000, p<.05)$ with a mean rank of 15.06 for the DOC with verb violation and 21.94 for the licensed DOC. It is worth noting that NSs' results had higher significance level and a bigger difference between the mean ranks of the tested sentence types. This is in accordance to the NEH prediction that bilinguals would be less sensitive to the tested violations and consequently would not differ the unlicensed sentences from the licensed ones as much as NSs would.

We also analyzed if the two experiments we conducted were comparable since they had methodological differences. As shown earlier, in Experiment 1 we used an acceptability judgment task with moving-window word-byword self-paced reading format and, in Experiment 2 we utilized a timed acceptability judgment task with six-second time limit.The two tasks had different formats because they were also used to collect data for two unrelated studies. Thus, we compared the data from the non-immersed high-proficiency bilingual groups from each experiment towards the DOC with verb violation and the licensed DOC in order to observe if these methodological differences generated different results. 
Graph 5 - Comparison between Experiment 1 and Experiment 2 non-immersed high proficiency bilinguals' acceptability ratings towards each sentence group.

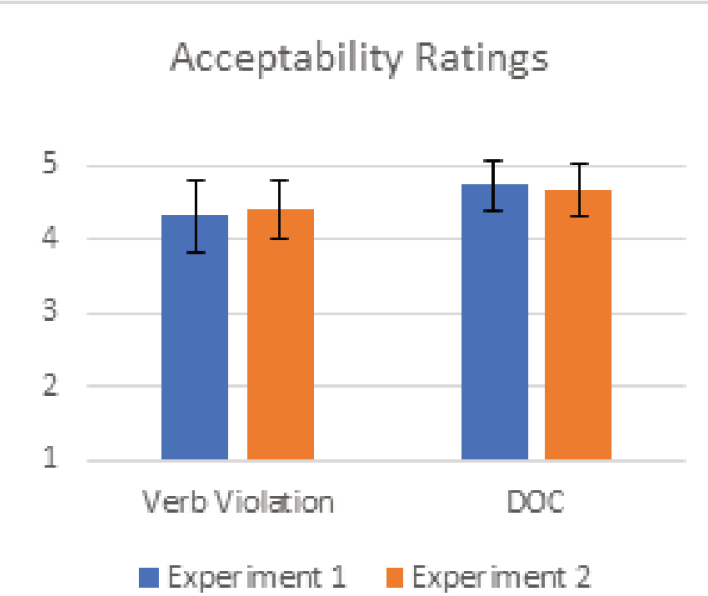

Graph 6 - Comparison between acceptability ratings to each sentence group within Experiment 1 and Experiment 2 non-immersed high proficiency bilinguals.

\section{Acceptability Ratings}

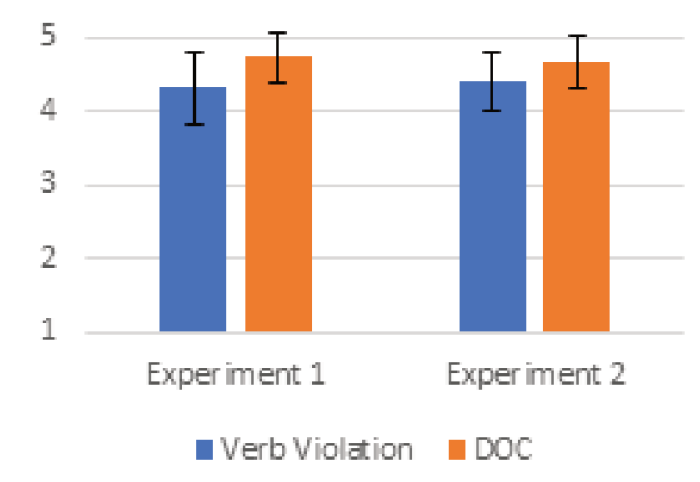

The comparisons between the two high proficiency bilingual groups, illustrated in Graph 5, did not yield significant differences. The group from Experiment 1 did not differ significantly from the group from Experiment 2 neither as to their acceptability ratings towards the DOC with verb violation ( $U$ $=151.500, p=.743$ ) with a mean rank of 17.92 for the former group and 19.08 for the latter, nor to their acceptability ratings towards the licensed $\mathrm{DOC}(\mathrm{U}=148.000$, $\mathrm{p}=.673$ ) with a mean rank of 19.28 for the former group and 17.72 for the latter. Furthermore, as illustrated in Graph 6 and reported in the previous experiments, both bilingual groups' acceptability ratings yielded a significant difference between the DOC with verb violation and the licensed DOC. Therefore, these results suggest that the methodological differences between Experiment 1 and Experiment 2 did not impact the results.

In the next section we will discuss our results and their implication to the fields of Second Language Acquisition/ Teaching.

\section{General Discussion}

The comparisons made in Experiment 1 and Experiment 2 corroborated our predictions, which were based on the NEH. In Experiment 1, bilinguals with lower proficiency levels did not differentiate the licensed from unlicensed DOC sentences, which indicated that bilinguals are likely to have difficulty learning that an L2-specific rule is only partially applicable. Also, the results from both experiments showed that at higher levels of proficiency bilinguals did differentiate the two DOC groups. However, as attested in Experiment 2, bilinguals, including those immersed in the L2, were not as sensitive to violations resulted from the overgeneralization of an L2-specific rule as compared to NSs.

The fact that bilinguals were less sensitive than NSs to this type violation suggests some possible differences between L1 and L2 acquisition/representation. 
As we have discussed, it is possible that NSs specify each possibility of argument structure in each verb, whereas bilinguals may exhibit a more top-down acquisition and use more general rules that may fail to include specific restrictions. If this is the case, bilinguals are likely to have difficulty learning that an L2-specific rule is only partially applicable, which is the basic rationale of the NEH. This weaker sensitivity may also suggest that bilinguals are more likely to produce this type of violation as compared to NSs. Naturally, that has to be investigated, but our study is a first indication that second language teachers and bilinguals themselves have to pay closer attention to the applicability limits of $\mathrm{L} 2$ rules.

We agree with Long (1991) that focus on meaning alone is not enough for bilinguals to achieve nativelike competence. We understand that bilinguals can benefit from focus on form in a manner that it will help them change their underlying competence. The key idea is that attention is paramount for successful learning, and so teachers should help students pay closer attention to different aspects of the language. It is important to highlight that by focus on form we do not mean decontextualized teaching of grammar rules, but instead we mean strategies that draw learners' attention to linguistic features that are relevant for them during negotiation of meaning in $\mathrm{L} 2$ activities focused on communication. Thus, activities focused on the negotiation of meaning should be used as the basis for focus on form in a manner that they will enhance the effectiveness of each other.

Hirakawa (2013) corroborates our view on how focus on form can help students increase their sensitivity to grammatical restrictions. The author presents results that indicate that explicit instruction was important for learners to become more sensitive to passivization errors, such as in "the earthquake was happened”. Endo, Shibuya and Hirakawa (2016) present similar results demonstrating that explicit instruction was more efficient than natural exposure in order to teach Japanese learners of English to master adjective ordering restrictions. Thus, we argue that focus on form may be helpful in making bilinguals more sensitive towards the violations that the NEH predicts will be difficult for bilinguals to perceive.

By way of illustration, we can consider the structures scrutinized in this paper. Imagine a BP-English bilingual with lower levels of proficiency, similar to the ones studied in Experiment 1, is learning English at school and is having trouble understanding a sentence such as "My friend sent me an e-mail" during an activity. The teacher can explain to the student that, in English, it is possible to use that structure instead of the one licensed in BP, John sent an e-mail to him, although the latter is also possible in English. However, if he ends his explanation here, the bilingual can easily overgeneralize the rule and produce the sentences below (37), which are some of the overgeneralizations of the DOC we saw in this paper. This is not to say that the teacher has to go through all possible violations, but he can mention the most generalizable ones (ex: Latinate constraint) or at least stress the existence of rule limits. Being conscious of the existence of these limits may be a first step for bilinguals to become more sensitive to these violations and less likely to produce them. 


$$
\begin{aligned}
& { }^{\star} \text { Smith threw the first base the ball. } \\
& { }^{\star} \text { John purchased Mary a car. } \\
& { }^{\star} \text { John donated Mary his money. }
\end{aligned}
$$

Our paper stresses the importance of focusing not only on grammatical forms, but also on ungrammatical forms. The violations under scrutiny in this paper do not seem to be frequently approached in L2 classes. As our result suggests, the fact that bilinguals learn the grammatical features of the DOC does not entail that they learn its restrictions. Considering that we analyzed data mostly from bilinguals with high proficiency, some of which have been immersed in the second language for more than 10 years, it seems that we have strong evidence that when bilinguals learn how to use a construction, the sensitivity to its restrictions does not come for free.

The results we obtained can also be interpreted from a methodological perspective. In Experiment 1, we used an untimed acceptability judgment task, which has been argued to tap into explicit knowledge, and in Experiment 2, we used an acceptability judgment task with a 6 second time limit, which has been argued to be more influenced by implicit knowledge (Ellis, 2005). However, in recent years, some studies have indicated that acceptability judgment tasks only rely on explicit knowledge regardless of time-ceiling impositions (Gutiérrez, 2013; Kim \& Nam, 2016; Souza, Soares-Silva \& Silva, 2016; Souza \& Oliveira, 2017). Oliveira (2016) argues that bilinguals' difficulty with violations, predicted by the NEH, will be observed in explicit knowledge, but not necessarily in implicit knowledge. The author tested the NEH with a timed acceptability judgment task and a maze-task, which is an online measure. The differences between bilinguals and monolinguals were only found in the first task, which suggests that the timed acceptability judgment task indeed taps into bilinguals' explicit knowledge. The fact that the two experiments in our study have not yielded significant differences also suggests that they have both tapped into bilinguals' explicit knowledge. Therefore, our study substantiates the findings of recent studies that propose that the acceptability judgment task is a measure of explicit knowledge regardless of time-ceiling impositions.

We hope our study can instigate future research .In our study, we formalized the NEH and presented results that support it. This hypothesis and the other theories about the limits of bilingualism we discussed can shed light on important issues related to bilingualism and second language acquisition/teaching, but they still need to be further investigated. The DOC also has many interesting peculiarities to be studied and is favored by its high frequency and cross linguistic variation as opposed to some other argument structure constructions. Finally, we hope to have brought important evidence about the type of knowledge tapped by the acceptability judgment paradigm. The comparison of results obtained via different protocols of data collection is crucial to the cumulative advancement of knowledge through scientific research. 
Notes

1. NP: Noun Phrase, VP: Verb Phrase, AP: Adjective Phrase.

2. Prepositional Phrase.

3. When we use the term "double-object construction" or DOC, it is to refer specifically to syntax which projects two direct objects. The term dative construction is used in this study to encompass the class of constructions which includes both the direct and the prepositional double-object structures.

4. Despite the use of the term alternation, we do not subscribe to the implications of such a term, in the sense that a surface form is derived from an underlying form, as presented in Larson (1988) or other generative framework.

5. (Green, 1974; Oehrle, 1976 in Hovavand Levin, 2008, p.144).

6. in Zara (2014, p. 65-68). Available at http://www.bibliotecadigital.ufmg.br/ dspace/handle/1843/MGSS-9HSMZ2 .

7. The size of the words was controlled because of another portion of the study which recorded chronometric measurements. This data have not yet been published.

\section{References}

Agirre, A. (2015). The acquisition of dative alternation in English by Spanish learners. Vigo International Journal of Applied Linguistics, 12, 63-90.

Agirre, A., \& Mayo, M. (2014). Double object constructions in L3 English: An exploratory study of morphological and semantic constraints. International Journal of English Studies, 14(2), 1-20.

Amaral, L., \& Roeper, T. (2014). Multiple Grammars and Second Language Representation. Second Language Research, 30(1), 3-36 doi: $10.1177 / 0267658313519017$.

Campbell, A. L., \& Tomasello, M. (2001). The acquisition of English dative constructions. Applied Psycholinguistics,22(2), 253-267. doi:10.1017/ s0142716401002065.

Carneiro, M. (2017). Investigating bilinguals' sensitivity to English regular past morphology: A self-paced reading experiment with Brazilian learners. Revista Brasileira de LinguísticaAplicada,17(3), 483-507. doi:10.1590/19846398201611101.

Dekeyser, R. M. (2005). What Makes Learning Second-Language Grammar Difficult? A Review of Issues. Language Learning,55(S1), 1-25. doi:10.1111/j.00238333.2005.00294.x.

Ellis, R. (2008). The study of second language acquisition. Oxford: Oxford Univ. Press.

Endo, M., Shibuya M., \& Hirakawa, M. (2016). Explicit Instruction vs. Natural Exposure in L2 Acquisition of Adjective Ordering in English. In D. Stringer et al. (eds.), Proceedings of the 13th Generative Approaches to Second Language Acquisition Conference (GASLA 2015) (pp. 60-71). Somerville, MA: Cascadilla Proceedings Project.

Ettlinger, M. (2005). The syntactic behavior of the resultative phrase: Evidence for a constructional approach. Annual Meeting of the Chicago Linguistic Society (Vol. 41, n.2, pp. 145-160).

Fernández, E. M., Souza, R. A., \& Carando, A. (2017). Bilingual innovations: Experimental evidence offers clues regarding the psycholinguistics of language change. Bilingualism: Language and Cognition, 20(2), 251-268. https://doi. org/10.1017/S1366728916000924. 
Fontoura, B. (2018). A Study of English L2 Users' Processing of Inflectional Morphemes and their Working Memory Capacity. (Master'sthesis, Universidade Federal de Minas Gerais, Belo Horizonte, Brazil). Retrieved from http://www. bibliotecadigital.ufmg.br/dspace/ handle/1843/LETR-AX8NJ6.

Forster, K., Guerrera, C., \& Elliot, L. (2009). The maze task: measuring forced incremental sentence processing time. Behavior Research Methods, 41(1), 163-17.

Goldberg, A., \& Jackendoff, R. (2004). The English Resultative as a family of constructions. Language, 80, 523-567.

Gomes, C. A. (2003). Dative alternation in Brazilian Portuguese: typology and constraints. Language Design Journal of Theoretical and Experimental Linguistics, 5, University of Granada, 67-78.

Green, G. (1974). Semantics and syntactic regularity. Bloomington, Indiana: Indiana University Press.

Gutiérrez, X. (2013).The construct validity of grammaticality judgment tests as measures of implicit and explicit knowledge. Studies in Second Language Acquisition, 35, 423-449.

Hamdan, J. (1994). Language transfer and the acquisition of the English dative alternation by native speakers of Arabic. (Doctoral dissertation, University of Reading, Reading, UK).

Harley, H. (2007). The bipartite structure of verbs cross-linguistically (or: Why Mary can't exhibit John her paintings). Text presented in ABRALIN conference, UFMG, Belo Horizonte, Brazil.

Hirakawa, M. (2013). Alternations and argument structure in second language English: Knowledge of two types of intransitive verbs. In M. Whong, K. Gil, \& H. Marsden (eds.), Universal grammar and the second language classroom (pp.117138). Dordrecht: Springer.

Hovav, M. R.; Levin, B. (2008). The English dative alternation: The case for verb sensitivity. J. Linguistics, 44, 129-167.

Inagaki, S. (2001). Motion verbs with goal PPs in the L2 acquisition of English and Japanese. Studies in Second Language Acquisition, 23, 153-170.

Jensen, I. N. (2016). The bottleneck hypothesis in L2 Acquisition. (Master's thesis, the Artic University of Norway), Tromsø, Norway.

Kang, S. (2011). The Acquisition of English dative constructions by Korean EFL Children. Proceedings of the 16th Conference of Pan-Pacific Association of Applied Linguistics. The Chinese University of Hong Kong. http://www.paaljapan.org/ conference2011/ ProcNewest2011/pdf/oral/1F-1.pdf.

Kim, J., \& Nam, H. (2016). Measures of implicit knowledge revisited - Processing modes, time pressure, and modalities. Studies in Second Language Acquisition,39(3), 431-457. doi:10.1017/S0272263115000510

Larson, R. (1988). On Double Object Constructions. Linguistic Inquiry, 19, 335-391.

Levin, B. (1993). English verb classes and alternations: A preliminary investigation. University of Chicago Press.

Long, M. (1991). Focus on Form: a design feature in language teaching methodology. In K. De Bot, R. B. Ginsberg, \& C. Kramasch (eds.), Foreign Language Research in Cross-Cultural Perspective (pp. 39-52). Amsterdam: John Benjamins. https://doi. org/ 10.1075/sibil.2.07lon.

Lucchesi, D. \& Mello, C. (2009). A alternância dativa no português afro-brasileiro: um processo de reestruturação original da gramática. Papia,19, 153-184. 
Maia, M. (2018). Psicolinguística e Educação. Campinas, SP: Mercado de Letras.

Mazurkewich, T. (1984). The acquisition of the dative alternation by second language learners and linguistic theory. Language Learning, 34, 91-109.

McDonnell, J. (2019). The second language acquisition of subject pronoun distribution in English, Italian and Polish: testing the Interface Hypothesis. (Doctoral dissertation, University of Essex), Colchester, UK.

Mikhaylova, A. (2018). Morphological bottleneck: The case of Russian heritage speakers. Journal of Language Contact, 11, 268-303

Montrul, S. (2001). First-language-constrained variability in the second-language acquisition of argument-structure-changing morphology with causative verbs. Second Language Research, 17, 144-194.

Nation, P. (1990). Teaching and learning vocabulary. Boston: Heinle\&Heinle.

Oehrle, R. (1976). The grammatical status of the English dative alternation. (Doctoral dissertation, MIT). Boston, MA. http://www.ai.mit.edu/projects/dm/theses/ oehrle76.pdf.

Oh, E. (2006). Second language acquisition of English double object constructions by Korean speakers. (Doctoral dissertation, University of Southern California) Los Angeles, California.

Okamoto, A. (2009). The importance of negative evidence in instructed second language acquisition. In D. Wei-Yang, L. Yiu-Nam, \& M. Jenks (Eds.), New Perspectives on English Instruction: Teaching, Learning, and Assessing (pp. 87-104). Taipei: Crane Publishing.

Oliveira, C. (2014).Uma investigação sobre a aquisição das regras de formação da construção resultativa por bilíngues de alta proficiência do par linguístico português do Brasil e inglês. Letrônica, (7)1, Porto Alegre, Brazil, 66-85.

(2016). The learnability, representation and processing of the resultative construction by Brazilian Portuguese-English bilinguals. (Doctoraldissertation, Universidade Federal de Minas Gerais, Belo Horizonte, Brazil).Retrieved from http://www.bibliotecadigital.ufmg.br/dspace/handle/1843/RMSA-AM2UMP.

Oliveira, C.; Souza, R.; Oliveira, F. (2017). Bilingualism effects on L1 representation and processing of argument structure. Journal of the European Second Language Association,1(1), 23-37. https://doi.org/10.22599/jesla.7.

Penzin, A. (2018). The processing of the double-object construction by Brazilian monolinguals and late Brazilian-Portuguese English bilinguals. (Master'sthesis, Universidade Federal de Minas Gerais, Belo Horizonte, Brazil). Retrieved from http://www.bibliotecadigital.ufmg.br/dspace/handle/1843/LETR-AZNMYX.

Pinker, S. (1989). Learnability and cognition: The acquisition of argument structure. Cambridge, MA: MIT Press.

Scher, A. P. (1996). Construções com dois complementos no inglês e no português do Brasil: um estudo sintático comparativo.(Master's thesis, UNICAMP, Campinas, Brazil). Retrieved from http://repositorio.unicamp.br/jspui/handle/ REPOSIP/271031.

Slabakova, R. (2014). The bottleneck of second language acquisition. Foreign Language Teaching and Research,(46)4, 543-559.

Sorace, A. (2011). Pinning down the concept of "interface" in bilingualism. Linguistic Approaches to Bilingualism,(1)1, 1-33.

Sorace, A., \& Filliaci, F. (2006). Anaphora resolution in near-native speakers of Italian. Second Language Research,22, 339-368. 
Sorace, A., \& Serratrice, L. (2009). Internal and external interfaces in bilingual language development: Beyond structural overlap. International Journal of Bilingualism,13, 195-210.

Souza, R., \& Oliveira, C. (2014). The learnability of the resultative construction in English L2: a comparative study of two forms of the acceptability judgment task. Revista da Abralin, 8 (2), 375-410.

(2017). Are bilingualism effects on the L1 byproducts of implicit knowledge? Evidence from two experimental tasks. Revista de Estudos da Linguagem, 25(3), 1685-1716.

Souza, R., Oliveira, C., Soares-Silva, J., Penzin, A., \& Santos, A. (2015). Estudo sobre um parâmetro de tarefa e um parâmetro amostral para experimentos com julgamentos de aceitabilidade temporalizados. Revista de Estudos da Linguagem, 23(1), 215-248.

Souza, R., \& Silva, J. (2015). Exploring the measurement of vocabulary size to differentiate Brazilian Portuguese-English bilinguals' access to grammatical knowledge in the L2. Linguistica, 11, 187-204.

Souza, R., Soares-Silva, J., \& Silva, G. (2016). Brazilian Portuguese-English bilingualism does not affect metalinguistic awareness of L1 constraints in two argument structure constructions. Ilha do Desterro,69(1), 17-32.

Wechsler, S. (2012). Resultatives and the problem of exceptions. In: Lee, Ik-Hwan. et al (eds.). Issues in English Linguistics (Papers from the 1st World Congress of Scholars of English Linguistics) (pp.119-131). Hanyang University, Seoul, South Korea. Hankookmunhwasa, Seoul.

White, L. (1989) Universal grammar and second language acquisition. Amsterdam: John Benjamins.

Yang, C., \& Montrul, S. (2016). Learning datives: The Tolerance Principle in monolingual and bilingual acquisition. Second Language Research,33(1), 119-144. https://doi.org/10.1177/0267658316673686.

Zara, J. V. (2009). Estudo da expressão de eventos de transferência de posse na interlíngua de brasileiros aprendizes de inglês. (Master's thesis, Universidade Federal de Minas Gerais Belo Horizonte, Brazil).

(2014). Togiveyou a book ortogive a book toyou: um estudo sobre a variação sintática na expressão linguística de eventos de transferência de posse na interlíngua português/inglês. (Doctoral dissertation, Universidade Federal de Minas Gerais, Belo Horizonte, Brazil). Retrieved from http://www.bibliotecadigital.ufmg.br/ dspace/ handle/1843/MGSS-9HSMZ2.

Zara, J. V., Oliveira, F. L., \& Souza, R. A. (2013). Selective transfer in the acquisition of double object constructions by Brazilian learners. Alfa: Revista de Linguística, (57)2, 519-544.

Zeddari, I. (2009). The Acquisition of the English Dative Alternation by Moroccan EFL University Learners: an Optimality-theoretic Approach. (Doctoral dissertation, University Mohammed V, Rabat, Morocco).

Recebido em: 15/02/2019 Aceito em: 22/07/2019 